\title{
Collaboration of community hospital endosonographers improves diagnostic yield of endoscopic ultrasonography guided tissue acquisition of solid pancreatic lesions
}

\section{(ㄷ)(우우}

\author{
Authors \\ Rutger Quispel ${ }^{1}$, Lydi M.J.W. van Driel ${ }^{2}$, Pieter Honkoop ${ }^{3}$, Mohamad Hadithi ${ }^{4}$, Marie-Paule Anten ${ }^{5}$, Frank Smedts ${ }^{6}$, \\ Margreet C. Kerkmeer ${ }^{7}$, Bart J. Veldt ${ }^{1}$, Marco J. Bruno ${ }^{2}$, On behalf of the Dutch, Rotterdam Regional, QUality in \\ EndoSonography Team (QUEST)
}

Institutions

1 Department of Gastroenterology and Hepatology, Reinier de Graaf Gasthuis, Delft, The Netherlands.

2 Department of Gastroenterology and Hepatology, Erasmus Medical Center, Rotterdam, The Netherlands.

3 Department of Gastroenterology and Hepatology, Albert Schweitzer Hospital, Dordrecht, The Netherlands.

4 Department of Gastroenterology and Hepatology, Maasstad Hospital, Rotterdam, The Netherlands.

5 Department of Gastroenterology and Hepatology, Sint Franciscus Hospital, Rotterdam, The Netherlands.

6 Department of Pathology, Reinier de Graaf Gasthuis, Delft, The Netherlands.

7 Department of Biostatistics and Education, "het Leerhuis", Reinier de Graaf Gasthuis, Delft, The Netherlands.

submitted 3.1.2019

accepted after revision 1.4 .2019

\section{Bibliography}

DOI https://doi.org/10.1055/a-0898-3389 |

Endoscopy International Open 2019; 07: E800-E807

(c) Georg Thieme Verlag KG Stuttgart · New York eISSN 2196-9736

\section{Corresponding author}

Rutger Quispel, MD, Department of Gastroenterology and Hepatology, Reinier de Graaf Gasthuis, Reinier de Graafweg 3, 2625 AD Delft, The Netherlands

Fax: +3115-2609111

r.quispel@rdgg.nl

\section{ABSTRACT}

Background and study aims Endoscopic ultrasound (EUS)-guided tissue acquisition (TA) is the method of choice for establishing a pathological diagnosis of solid pancreatic lesions. Data on quality and yield of EUS-guided TA performed in community hospitals are lacking. A study was performed to determine and improve the diagnostic yield of EUS-guided TA in a group of community hospitals. Methods Following analysis of the last 20 EUS-guided TA procedures of solid pancreatic lesions performed in each of four community hospitals, a collaborative EUS interest group was formed and a prospective registry was started. During meetings of the interest group, feedback on results per center were provided and strategies for improvement were discussed.

Results In the BEFORE team formation cohort, 80 procedures were performed in 66 patients. In the AFTER team formation cohort, 133 procedures were performed in 125 patients. After team formation, the rate of adequate sample increased from $80 \%(95 \% \mathrm{Cl}[0.7-0.9])$ to $95 \%(95 \% \mathrm{Cl}$ [0.9-1.0]), diagnostic yield of malignancy improved from $28 \%(95 \% \mathrm{Cl}[0.2-0.4])$ to $64 \%(95 \% \mathrm{Cl}[0.6-0.7])$, and sensitivity of malignancy improved from $63 \%(95 \% \mathrm{Cl}$ $[0.4-0.8])$ to $84 \%(95 \% \mathrm{Cl}[0.8-0.9])$. Multivariate regression analysis revealed team formation to be the only variable significantly associated with an increased rate of adequate sample.

Conclusions Formation of a regional EUS interest group with regular feedback on results per center, and discussions on methods and techniques used, significantly improved the outcome of EUS-guided TA procedures in patients with solid pancreatic lesions in community hospitals.

\section{Introduction}

Use of endoscopic ultrasound (EUS)-guided tissue acquisition (TA) of pancreatic lesions has increased dramatically over the last 20 years [1]. Following the initial publication on this sub- ject, EUS-guided TA has become the method of choice to establish a pathological diagnosis of solid pancreatic lesions [2].

EUS-guided TA of solid lesions of the pancreas is reported to have a sensitivity of $85 \%$, a specificity of $98 \%$ and a diagnostic accuracy of $88 \%[3,4]$. In 2015, the ASGE published quality indicators defining performance targets for EUS-guided fine-nee- 
dle aspiration (FNA) of solid pancreatic lesions: 1. rate of adequate sample $85 \%$; 2 . diagnostic yield of malignancy $70 \%$; and 3. sensitivity of malignancy $85 \%$ [5]. EUS-guided TA of solid pancreatic lesions is a complex, multistep process in which several equipment and operator variables may impact the diagnostic yield. Factors such as: needle size, needle type, amount and type of suction applied, number of passes, presence of onsite cytopathological evaluation, and operator experience have been extensively studied in well-designed randomized trials [6-16]. These studies have almost exclusively been performed in tertiary referral centers.

Data regarding practice variation in pancreatic EUS-guided TA are limited. In a large multicenter retrospective study, including 1075 patients with solid pancreatic lesions from 21 centers, they found the diagnostic yield of malignancy per center ranging from $39 \%$ to $93 \%$ (first quartile $61 \%$; third quartile $85 \%)$. The majority of these ( $81 \%$ ) were academic centers, all but one located in the United states [17]. A recent publication found marked regional differences regarding use of EUS and EUS-guided TA in the province of Ontario, Canada [18]. These publications both show significant differences regarding EUS practice and yield between different centers and different regions.

In the Netherlands, as in many other countries, EUS-guided TA is also practiced in the majority of larger community hospitals. Data in the literature are lacking on results of EUS-guided TA from solid pancreatic lesions in community hospitals. We performed a study in patients with solid pancreatic lesions aiming to: 1. determine practice variation regarding yield of EUSguided TA in patients with solid pancreatic lesions; and 2. improve quality and yield of EUS-guided TA in a collaborative group of four community hospitals in the Rotterdam region, Zuid-Holland, the Netherlands.

\section{Methods}

First, we retrospectively analyzed the diagnostic performance of the last consecutive 20 EUS-guided TA procedures of solid pancreatic lesions in each of the 4 community hospitals in the province of Zuid-Holland in the Netherlands (the BEFORE cohort). These procedures had all been performed in 2014.

Next, from January 2015 on, a regional EUS interest group was formed and regular team meetings were organized. The formation of this interest group and its three annual meetings was initiated and organized by community hospital endosonographers. Endosonographers and trainees from the local tertiary center were involved from the beginning and attended all meetings. At the first meeting, the results of the retrospective analysis were extensively discussed, as were possible strategies to reduce practice variation and improve diagnostic yield. At subsequent meetings, guidelines, techniques and materials, and tips and tricks were exchanged by means of formal presentations and open discussions, and EUS case video recordings were presented and discussed.

Prospective data were collected between January 2015 and September 2016 (The AFTER cohort). During this period, five EUS interest group meetings were organized. Feedback on per- formance per center was provided once a year. Based on data provided during team meetings, each local endosonography team decided to change or maintain their practice. No specific protocols or materials were prescribed by the regional team or any of its members.

The primary outcome variable for both cohorts was rate of adequate sample, defined as proportion of procedures yielding specimen sufficient for cytological and/or histological analysis. Secondary outcome variables were diagnostic yield of malignancy: proportion of procedures yielding a malignant diagnosis; sensitivity for malignancy: true positives divided by the sum of true positives and false negatives; and diagnostic accuracy defined as the sum of true positives and true negatives divided by the total number of diagnostic procedures. The primary and secondary outcome variables, except diagnostic accuracy, were previously defined as ASGE quality indicators.

Data on EUS-guided TA procedures collected from both the BEFORE, and AFTER cohorts included: patient demographics, localization of the pancreatic mass, hospital, endosonographer, needle diameter (19-22-25 G), number of passes, use of any suction technique (yes/no) and the result of the cytological and/or histopathological evaluation of the EUS-guided TA specimen, and whether an EUS-guided TA procedure was repeated following the initial procedure. The results of cytological and/or histopathological evaluation were stratified as follows: malignant, non-malignant, unclear, and non-diagnostic i.e. insufficient material for diagnosis. As a reference standard, the final diagnosis based on a minimum of 12 months of clinical followup and/or histopathology and/or surgical resection specimen was used.

In the AFTER cohort, additional data were collected including tumor size, ultrasonography characteristics of the mass (echogenicity, vascularity, delineation, homogeneity), consistency of the mass, puncture location (ie. stomach or duodenum), type of EUS needle (fine-needle aspiration[FNA]/fineneedle biopsy [FNB]), type of suction (vacuum/slow withdrawal of stylet), type of liquid-based cytology (LBC) medium used (Cytolyt, Cytotich Red, other), and presence of on-site cytopathological evaluation during EUS-guided TA.

In each of the collaborating hospitals, 200 to 300 EUS procedures are performed annually. All endosonographers were formally trained in endosonography for at least 1 year at a referral center. During formal training, each endosonographer performed at least 250 EUS procedures, including 100 pancreaticobiliary cases and at least 50 EUS-guided TA procedures. Post-training EUS experience ranged from 1 to 12 years while performing an average of 80 procedures per year (range 60 200). Patient selection and techniques and materials used were all at the discretion of the local clinicians and according to local availability of equipment and hospital standards.

\section{Statistics}

To detect a significant difference in the rate of adequate sample from $80 \%$ to $95 \%$, with $\alpha=0.05$ and power of 0.9 , the required number of procedures in the AFTER cohort is 97.

Data are presented as median and range for continuous variables, and as counts with percentages for categorical variables. 
- Table 1 Demographics, tumor localization and reference standard per EUS guided TA procedure in BEFORE and AFTER cohorts.

\begin{tabular}{|c|c|c|c|c|}
\hline & $\begin{array}{l}\text { Total } \\
(n=213)\end{array}$ & $\begin{array}{l}\text { BEFORE } \\
(n=80)\end{array}$ & $\begin{array}{l}\text { AFTER } \\
(n=133)\end{array}$ & $\begin{array}{l}P \text { value } \\
\text { (BTF vs ATF) }\end{array}$ \\
\hline Sex male, $n(\%)$ & $116(54 \%)$ & $46(58 \%)$ & $70(52 \%)$ & 0.5 \\
\hline Median age in years (range) & $69(24-87)$ & $67(24-86)$ & $70(43-87)$ & 0.02 \\
\hline Location mass pancreatic head, $n(\%),[95 \% \mathrm{Cl}]$ & $\begin{array}{l}125(59 \%) \\
{[0.5-0.7]}\end{array}$ & $\begin{array}{l}50(63 \%) \\
{[0.5-0.7]}\end{array}$ & $\begin{array}{r}75(56 \%) \\
{[0.5-0.7]}\end{array}$ & 0.4 \\
\hline Reference standard malignant, $\mathrm{n}(\%),[95 \% \mathrm{Cl}]$ & $\begin{array}{l}177(83 \%) \\
{[0.8-0.9]}\end{array}$ & $\begin{array}{l}58(72 \%) \\
{[0.6-0.8]}\end{array}$ & $\begin{array}{l}118(89 \%) \\
{[0.8-0.9]}\end{array}$ & $<0.01$ \\
\hline
\end{tabular}

Point estimates are presented with $95 \%$ confidence intervals (Cls). Categorized variables were analyzed using Fisher's exact test or chi-square test, as appropriate. Quantitative variables were analyzed using Welch's t-test. A Mann-Whitney U Test was used for not normally distributed variables.

Sensitivity and diagnostic accuracy were calculated using $2 \times 2$ contingency tables and compared using $n-1$ chi-square testing [19].

Univariate logistic regression analysis was performed to identify factors associated with rate of adequate sample. Variables with $P<0.1$ during univariate analysis were tested in a multivariate model.

The study protocol was approved by the local ethics committees of the four hospitals.

\section{Results}

Between September 2014, and September 2016, 213 consecutive EUS-guided TA procedures of solid pancreatic lesions were included in our study. The BEFORE cohort consisted of 66 unique patients who underwent a total of 80 EUS-guided TA procedures. The AFTER cohort consisted of 125 unique patients who underwent a total of 133 procedures.

In the BEFORE cohort, patients were significantly younger in comparison to the AFTER cohort. In the AFTER cohort, the proportion of patients with a final diagnosis of pancreatic malignancy (= reference standard) was higher in comparison to the BEFORE cohort $(89 \%,(95 \% \mathrm{Cl}[0.8-0.9])$ vs $72 \%,(95 \% \mathrm{Cl}[0.6-$ 0.8]) ( Table 1).

The number of patients in whom a second procedure was performed to achieve diagnostic accuracy decreased from 14 out of $80(18 \%, 95 \% \mathrm{Cl}[0.1-0.3])$ in the BEFORE cohort to nine out of $133(7 \%, 95 \% \mathrm{Cl}[0.03-0.13])$ in the AFTER cohort. Twenty of 22 patients $(91 \%, 95 \% \mathrm{Cl}[0.7-1.0])$ with a non-diagnostic procedure were finally diagnosed with a pancreatic malignancy.

In the BEFORE cohort the rate of adequate sample per hospital differed significantly (55\%: $95 \% \mathrm{Cl}[0.3-0.8]$ to $100 \%$ : $95 \%$ $\mathrm{Cl}[0.8-1.0])(\triangleright$ Table 2$)$. In the AFTER cohort the overall rate of adequate sample increased from $80 \%(95 \% \mathrm{Cl}[0.7-0.9])$ to $95 \%$ (95\% Cl [0.9-1.0]). Nevertheless, significant differences remained in the rate of adequate sample between individual hospitals, ranging from $83 \%(95 \% \mathrm{Cl}[0.6-0.9])$ to $100 \%(95 \%$ $\mathrm{Cl}[0.9-1.0])$.

In the BEFORE cohort diagnostic yield of malignancy per hospital ranged from $0 \%(95 \% \mathrm{Cl}[0.0-0.2])$ to $55 \%(95 \% \mathrm{Cl}$ [0.3-0.8]), compared with $59 \%(95 \% \mathrm{Cl}[0.4-0.8])$ to $67 \%$ $(95 \% \mathrm{Cl}[0.5-0.8])$ in the AFTER cohort. In the AFTER cohort differences between the hospitals regarding diagnostic yield were no longer statistically significant (difference $18 \%, 95 \% \mathrm{Cl}$ [-0.2-0.3], $P=0.5)$ Overall, diagnostic yield of malignancy in the AFTER cohort improved significantly from $28 \%(95 \% \mathrm{Cl}$ [0.2-0.4] to $64 \%(95 \% \mathrm{Cl}[0.6-0.7])$, (difference $36 \%, 95 \% \mathrm{Cl}$ $[0.2-0.5])$.

Sensitivity for malignancy was significantly different between hospitals in the BEFORE cohort, ranging from $50 \%$ (95\% $\mathrm{Cl}[0.1-0.9])$ to $89 \%(95 \% \mathrm{Cl}[0.5-1.0])$, (difference $39 \%, 95 \%$ $\mathrm{Cl}[0.1-0.6])$. In the AFTER cohort, it ranged from $62 \%(95 \% \mathrm{Cl}$ $[0.4-0.8])$ to $92 \%(95 \% \mathrm{Cl}[0.7-1.0])$, (difference $30 \%, 95 \% \mathrm{Cl}$ [0.1-0.5]). Overall, sensitivity for malignancy improved from $63 \%(95 \% \mathrm{Cl}[0.4-0.8])$ to $84 \%(95 \% \mathrm{Cl}[0.8-0.9])$, (difference $21 \%, 95 \% \mathrm{Cl}[0.1-0.3])$.

Diagnostic accuracy was also different between hospitals in the BEFORE cohort ranging from $36 \%(95 \% \mathrm{Cl}[0.1-0.6])$ to $70 \%$ (95\% Cl [0.5-0.9], (difference 34\%, 95\% Cl [0.0-0.6]). In the AFTER cohort the overall diagnostic accuracy improved from $58 \%(95 \% \mathrm{Cl}[0.4-0.7])$ to $74 \%(95 \% \mathrm{Cl}[0.7-0.8])$, (difference $16 \%, 95 \% \mathrm{Cl}[0.0-0.3])$.

\section{Effect of team formation on endosonography behavior}

In the AFTER cohort the median number of passes increased significantly from 2.0 (range $1-5$ ) to 3.0 (range 1-6) ( $\mathbf{T a -}$ ble 3$)$. In the BEFORE cohort only one pass was performed in 29 out of 80 cases (36\%) compared to 14 out of 131 (11\%) in the AFTER cohort ( $\triangleright$ Fig. 1). Overall the diagnostic yield for malignancy of one pass was $32 \%(95 \% \mathrm{Cl}[0.2-0.5])$ compared to a diagnostic yield of more than one pass (range $2-6$ ) of $51 \%$ (95\% Cl [0.4-0.6]), (difference 19\%, 95\% Cl [0.0-0.3]).

In hospitals $B$ and $C$ the median number of passes did not significantly change. In hospital A the median number of passes increased from 2.0 to 3.0 in the AFTER cohort $(95 \% \mathrm{Cl}[0.3-$ 
- Table 2 Performance characteristics per hospital BEFORE and AFTER.

\begin{tabular}{|c|c|c|c|c|c|c|c|c|}
\hline & A & B & C & D & $\begin{array}{l}\text { Difference } \\
\text { (min-max) }\end{array}$ & $95 \% \mathrm{Cl}$ & $P$ value & Total \\
\hline Procedures BEFORE & 20 & 20 & 20 & 20 & & & & 80 \\
\hline $\begin{array}{l}\text { Rate of adequate } \\
\text { sample }\end{array}$ & $\begin{array}{l}70 \% \\
{[0.5-0.9]}\end{array}$ & $\begin{array}{l}95 \% \\
{[0.7-1.0]}\end{array}$ & $\begin{array}{l}100 \% \\
{[0.8-1.0]}\end{array}$ & $\begin{array}{l}55 \% \\
{[0.3-0.8]}\end{array}$ & $45 \%$ & {$[0.2-0.7]$} & $<0.001$ & $\begin{array}{l}80 \% \\
{[0.7-0.9]}\end{array}$ \\
\hline $\begin{array}{l}\text { Diagnostic yield of } \\
\text { malignancy }\end{array}$ & $\begin{array}{l}0 \% \\
{[0.0-0.2]}\end{array}$ & $\begin{array}{l}40 \% \\
{[0.3-0.7]}\end{array}$ & $\begin{array}{l}55 \% \\
{[0.3-0.8]}\end{array}$ & $\begin{array}{l}15 \% \\
{[0.1-0.7]}\end{array}$ & $55 \%$ & {$[0.3-0.7]$} & $<0.001$ & $\begin{array}{l}28 \% \\
{[0.2-0.4]}\end{array}$ \\
\hline $\begin{array}{l}\text { Sensitivity for } \\
\text { malignancy }\end{array}$ & $\ldots$ & $\begin{array}{l}89 \% \\
{[0.5-1.0]}\end{array}$ & $\begin{array}{l}79 \% \\
{[0.5-0.9]}\end{array}$ & $\begin{array}{l}50 \% \\
{[0.1-0.9]}\end{array}$ & $39 \%$ & {$[0.1-0.6]$} & $<0.01$ & $\begin{array}{l}63 \% \\
{[0.4-0.8]}\end{array}$ \\
\hline Diagnostic accuracy & $\begin{array}{l}36 \% \\
{[0.1-0.6]}\end{array}$ & $\begin{array}{l}68 \% \\
{[0.4-0.9]}\end{array}$ & $\begin{array}{l}70 \% \\
{[0.5-0.9]}\end{array}$ & $\begin{array}{l}45 \% \\
{[0.2-0.8]}\end{array}$ & $34 \%$ & {$[0.0-0.6]$} & & $\begin{array}{l}58 \% \\
{[0.4-0.7]}\end{array}$ \\
\hline Procedures AFTER & 24 & 23 & 49 & 37 & & & & 133 \\
\hline $\begin{array}{l}\text { Rate of adequate } \\
\text { sample }\end{array}$ & $\begin{array}{l}83 \% \\
{[0.6-0.9]}\end{array}$ & $\begin{array}{l}96 \% \\
{[0.8-1.0]}\end{array}$ & $\begin{array}{l}100 \% \\
{[0.9-1.0]}\end{array}$ & $\begin{array}{l}97 \% \\
{[0.8-1.0]}\end{array}$ & $17 \%$ & {$[0.0-0.4]$} & $<0.01$ & $\begin{array}{l}95 \% \\
{[0.9-1.0]}\end{array}$ \\
\hline $\begin{array}{l}\text { Diagnostic yield of } \\
\text { malignancy }\end{array}$ & $\begin{array}{l}60 \% \\
{[0.4-0.8]}\end{array}$ & $\begin{array}{l}59 \% \\
{[0.4-0.8]}\end{array}$ & $\begin{array}{l}65 \% \\
{[0.5-0.8]}\end{array}$ & $\begin{array}{l}67 \% \\
{[0.5-0.8]}\end{array}$ & $18 \%$ & {$[-0.2-0.3]$} & 0.5 & $\begin{array}{l}64 \% \\
{[0.6-0.7]}\end{array}$ \\
\hline $\begin{array}{l}\text { Sensitivity for } \\
\text { malignancy }\end{array}$ & $\begin{array}{l}75 \% \\
{[0.5-0.9]}\end{array}$ & $\begin{array}{l}62 \% \\
{[0.4-0.8]}\end{array}$ & $\begin{array}{l}84 \% \\
{[0.7-0.9]}\end{array}$ & $\begin{array}{l}92 \% \\
{[0.7-1.0]}\end{array}$ & $30 \%$ & {$[0.1-0.5]$} & $<0.01$ & $\begin{array}{l}84 \% \\
{[0.8-0.9]}\end{array}$ \\
\hline Diagnostic accuracy & $\begin{array}{l}70 \% \\
{[0.5-0.9]}\end{array}$ & $\begin{array}{l}64 \% \\
{[0.4-0.8]}\end{array}$ & $\begin{array}{l}73 \% \\
{[0.6-0.8]}\end{array}$ & $\begin{array}{l}83 \% \\
{[0.7-0.9]}\end{array}$ & $19 \%$ & {$[0.0-0.4]$} & 0.09 & $\begin{array}{l}74 \% \\
{[0.7-0.8]}\end{array}$ \\
\hline \multicolumn{9}{|c|}{$\begin{array}{l}\text { A, B, C and D represent collaborating community hospitals. } \\
\text { Rate of adequate sample: proportion of procedures yielding specimen sufficient for cytological and/or histopathological analysis (\%, [95\% Cl]). } \\
\text { Diagnostic yield of malignancy: proportion of procedures yielding a malignant diagnosis (\%, [95\% Cl]). } \\
\text { Sensitivity of malignancy: true positives divided by the sum of true positives and false negatives }(\%,[95 \% \mathrm{Cl}]) \text {. } \\
\text { Diagnostic accuracy: true positives + true negatives divided by total number of procedures (\%, [95\% Cl]). } \\
\text { Significant results are bolded }\end{array}$} \\
\hline
\end{tabular}

1.4]). In Hospital $D$ the median number of passes increased from 2.5 to 3.0 in the AFTER cohort $(95 \% \mathrm{Cl}[0.6-1.6])$.

In the AFTER cohort the use of $19 \mathrm{G}$ needles overall decreased from $18 \%$ to $8 \%$ (difference $10 \%, 95 \% \mathrm{Cl}[0.01-0.2]$ ) and a trend was observed towards more frequent use of the 25G needle ( $\triangleright$ Table 3 ). In hospitals $B$ and $C$ needle diameters did not significantly change. In hospital A the $25 \mathrm{G}$ needle was introduced after team formation and used in 10 of 24 cases (42\%). Use of $22 \mathrm{G}$ needles in this hospital was reduced from $100 \%$ to $58 \%$ accordingly (difference $42 \%, 95 \% \mathrm{Cl}[0.2-0.6]$ ). In hospital D use of the $19 \mathrm{G}$ needles decreased from $65 \%$ to $8 \%$ in the AFTER cohort (difference $57 \%, 95 \% \mathrm{Cl}[0.3-0.7]$ ).

Although use of suction in the BEFORE cohort was only reported in $53 \%$ of cases (with 38 out of 80 missing), use of any type of suction overall increased from $35 \%$ to $96 \%$ in the AFTER cohort (difference $61 \%, 95 \% \mathrm{Cl}[0.5-0.7]$ ). In the BEFORE cohort hospitals $B$ and $D$ did not report on use of suction in the majority of cases. In hospitals $A$ and $C$ use of suction was reported in both cohorts ( $\triangleright$ Table 3 ).

\section{Variables associated with non-diagnostic procedures in univariate and multivariate analysis}

In univariate regression analysis formation of a regional team of endosonographers and decreased use of 196 needles were associated with a reduced proportion of non-diagnostic proce- dures i.e. an increased rate of adequate sample ( $\downarrow$ Table 4). Multivariate regression analysis, including use of $19 \mathrm{G}$ needles (yes/no), and before/after team formation in the model, showed only the latter variable to be significantly associated with an increased rate of adequate sample (OR 5, 95\% Cl [213], $P<0.01)$.

\section{Practice variation in the AFTER cohort}

In the AFTER cohort significant differences between the centers remained regarding choice of type and diameter of needle, number of passes performed, use of suction, type of suction, presence of on-site cytopathological evaluation, and choice of liquid-based cytology medium.

The median number of passes performed per hospital ranged from 1.0 in hospital $B$ to 3.0 in hospitals D (difference 2.0, $95 \% \mathrm{Cl}[1.8-2.6]$ ) ( Table 3). Center A used FNA needles only, compared to center C using FNB needles in $80 \%$. Centre $B$ used 25G FNA needles in 78\%, whereas center D mostly used 22G FNA and/or FNB needles. In 42 of 133 cases (32\%) on-site cytopathological evaluation was available during EUS-guided TA, ranging from $0 \%$ to $47 \%$ in the different hospitals. In two of four centers no on-site cytopathological evaluation was available. We observed a trend towards performing fewer passes with FNB/core needles in comparison to FNA needles. 
- Table 3 Number of passes, needle diameters and suction applied per hospital BEFORE and AFTER.

\begin{tabular}{|c|c|c|c|c|}
\hline \multicolumn{2}{|l|}{ BEFORE } & \multicolumn{3}{|l|}{ AFTER } \\
\hline A: & $\mathbf{N}=\mathbf{2 0}$ & $N=24$ & $P$ value & $95 \% \mathrm{Cl}$ \\
\hline Passes (median (range)) & $2.0(1-4)$ & $3.0(2-4)$ & $<0.01$ & $0.3-1.4$ \\
\hline $25 G$ & - & $10(42 \%)$ & $<0.01$ & $0.2-0.6$ \\
\hline $22 G$ & $20(100 \%)$ & $14(58 \%)$ & $<0.01$ & $0.2-0.6$ \\
\hline $19 G$ & - & - & & \\
\hline Needle not reported & - & - & & \\
\hline Any suction & $16(80 \%)$ & $24(100 \%)$ & 0.02 & $0.02-0.4$ \\
\hline Suction not reported & - & - & & \\
\hline B: & $N=20$ & $N=23$ & & \\
\hline Passes (median (range)) & $1.0(1-2)$ & $1.0(1-2)$ & 0.1 & $-0.1-0.5$ \\
\hline $25 G$ & $18(90 \%)$ & $15(65 \%)$ & 0.06 & $-0.01-0.5$ \\
\hline $22 G$ & $1(5 \%)$ & $2(9 \%)$ & 0.6 & $-0.2-0.2$ \\
\hline $19 G$ & $1(5 \%)$ & $4(17 \%)$ & 0.2 & $-0.1-0.3$ \\
\hline Needle not reported & - & $2(9 \%)$ & & \\
\hline Any suction & - & $21(91 \%)$ & (a) & \\
\hline Suction not reported & $20(100 \%)$ & $2(9 \%)$ & & \\
\hline C: & $N=\mathbf{2 0}$ & $N=49$ & & \\
\hline Passes (median (range)) & $3.0(1-5)$ & $3.0(2-5)$ & 0.4 & $-0.3-0.6$ \\
\hline $25 G$ & $6(30 \%)$ & $23(46.9 \%)$ & 0.2 & $-0.1-0.4$ \\
\hline $22 \mathrm{G}$ & $14(70 \%)$ & $23(46.9 \%)$ & 0.08 & $-0.03-0.4$ \\
\hline $19 G$ & - & $3(6.1 \%)$ & 0.3 & $-0.1-0.2$ \\
\hline Needle not reported & - & - & & \\
\hline Any suction & $11(55 \%)$ & 47 (96\%) & $<0.001$ & $0.2-0.6$ \\
\hline Suction not reported & - & - & & \\
\hline D: & $N=20$ & $N=37$ & & \\
\hline Passes (median (range)) & $2.5(1-4)$ & $3.0(2-6)$ & $<0.001$ & $0.6-1.6$ \\
\hline $25 G$ & - & $2(5 \%)$ & 0.3 & $-0.1-0.2$ \\
\hline $22 \mathrm{G}$ & $5(25 \%)$ & $32(87 \%)$ & $<0.001$ & $0.6-0.9$ \\
\hline $19 G$ & $13(65 \%)$ & $3(8 \%)$ & $<0.001$ & $0.3-0.7$ \\
\hline Needle not reported & $2(10 \%)$ & - & & \\
\hline Any suction & $1(5 \%)$ & $36(97 \%)$ & (a) & \\
\hline Suction not reported & $18(90 \%)$ & $1(3 \%)$ & & \\
\hline Total & $N=80$ & $N=133$ & & \\
\hline Passes (median (range)) & $2.0(1-5)$ & $3.0(1-6)$ & $<0.001$ & $0.5-1.0$ \\
\hline $25 G$ & $24(30 \%)$ & $50(38 \%)$ & 0.2 & $-0.1-0.2$ \\
\hline $22 \mathrm{G}$ & $40(50 \%)$ & $71(54 \%)$ & 0.7 & $-0.1-0.2$ \\
\hline $19 G$ & $14(18 \%)$ & $10(8 \%)$ & 0.03 & $0.01-0.2$ \\
\hline Needle not reported & $2(3 \%)$ & $2(2 \%)$ & & \\
\hline
\end{tabular}


- Table 3 (Continuation)

\begin{tabular}{|c|c|c|c|c|}
\hline \multicolumn{2}{|l|}{ BEFORE } & \multicolumn{3}{|l|}{ AFTER } \\
\hline Any suction & $28(35 \%)$ & $128(96 \%)$ & $<0.001^{*}$ & $0.5-0.7$ \\
\hline Suction not reported & $38(48 \%)$ & $3(2 \%)$ & & \\
\hline
\end{tabular}

- Table 4 Variables associated with non-diagnostic procedures in univariable and multivariable analysis.

\begin{tabular}{|l|l|l|l|}
\hline & Univariate (1) & Multivariate \\
\hline Variable & Odds ratio with $\mathbf{9 5 \% C l}$ & Odds ratio with 95\%Cl \\
\hline Needle diameter 19G (yes/no) & $0.4(0.1-1.1)$ & 0.08 & $\mathbf{P}$ value \\
\hline AFTER (yes/no) & $5(2-14)$ & $\mathbf{0 . 0 0 1}$ & $5(2-13)$ \\
\hline $\begin{array}{l}\text { Results of univariate logistic regression analysis investigating nine variables as potential predictors of non-diagnostic procedures, and of the multivariate analysis } \\
\text { using variables significant at } P<0.1 \text { in the univariate analysis. } \\
\text { Age, sex, mass localization (pancreatic head yes/no), number of passes (<3 yes/no), use of any type of suction (yes/no), endosonographer experience (>3 years post- } \\
\text { training yes/no), and endosonographer training program (Erasmus Medical Center yes/no) had } P \text { values }>0.1 \text { in univariate analysis and were therefore not included in } \\
\text { the multivariate analysis. } \\
\text { Significant results are bolded }\end{array}$
\end{tabular}

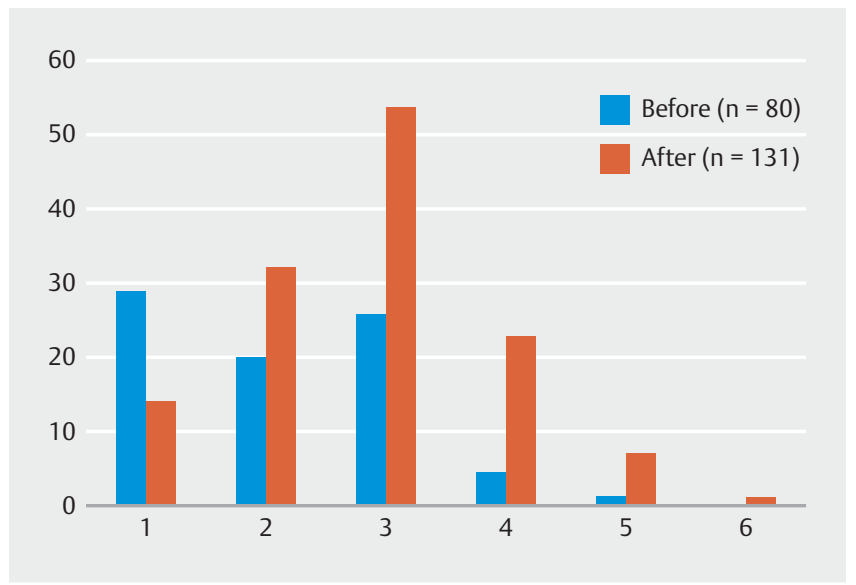

- Fig. 1 On the X-axis the number of passes performed per procedure. On the $\mathrm{Y}$-axis the number of procedures performed.

None of the technical aspects of the procedure (i.e. puncture location, type of needle, type of suction, use of stylet, type of liquid-based cytology medium used, or presence of onsite cytopathological evaluation) were significantly related to rate of adequate sample or diagnostic yield for malignancy in univariate and multivariate regression analysis.

\section{Adverse events}

One case of post EUS-guided TA pancreatitis was reported in the AFTER cohort, requiring hospitalization for 2 days. No other adverse events were reported.

\section{Discussion}

Formation of a regional EUS interest group with regular team meetings that include presentations of EUS case video recordings, literature discussions, and feedback on performance per center pending this study significantly improved the outcome of EUS-guided TA in patients with solid lesions of the pancreas in community hospitals and reduced practice variation.

By means of this intervention, the adequacy of the samples increased from $80 \%$ to $95 \%$. Diagnostic yield of malignancy increased from $28 \%$ to $64 \%$. Sensitivity for malignancy increased from $63 \%$ to $84 \%$, and diagnostic accuracy from $58 \%$ to $74 \%$. As a consequence, the proportion of patients requiring a second EUS-guided TA procedure to achieve an adequate diagnosis was reduced from $18 \%$ to $7 \%$.

Practice variation was reduced regarding techniques used (behavior of endosonographers) and outcome. The two hospitals that initially were underperforming showed an improvement up to the level of the two other hospitals. In the AFTER cohort only minor differences between hospitals regarding outcome of EUS-guided TA remained.

Team formation led to changes in behavior of endosonographers. Significant changes in behavior were made in both initially underperforming hospitals $A$ and D. After team formation, EUS-guided TA procedures in patients with solid pancreatic lesions in these hospitals involved more passes, use of less $19 \mathrm{G}$ and more $25 \mathrm{G}$ needles, and more consequent use of suction, and therefore were more in line with the guidelines [20]. It remains unclear whether and to what extent these changes affected outcome.

The fact that hospitals $B$ and $C$, both with reasonable outcomes in both BEFORE and AFTER cohorts, also deviated from 
the guidelines does not add to clarity regarding this subject. This is illustrated by the low median number of passes in hospital B, in both BEFORE and AFTER cohorts (1.0 in both cases) in contrast with the guidelines, which suggest three to four passes be made with an FNA needle and two to three passes with an FNB needle.

Besides, multivariate logistic regression does not support that changes regarding behavior have led to an improved outcome. This may be due to the limited sample size, but may also suggest that non-measured variables play a role. It appears that the improved yield in our study is related to more than just the “technical” variables measured. The endosonographers' (postgraduate) learning curve, the quality of the preparation of smears, the techniques used at the cytopathology lab, the experience of the local cytopathologist, and the quality of communication with the local cytopathologist are examples of variables likely to be involved.

Taking into consideration the differences in median age and reference standard between the groups BEFORE and AFTER, case selection was also affected. The increased proportion of patients with a malignancy after team formation may partially be explained by the currently higher demand for EUS-guided TA in individuals with solid pancreatic lesions expected to undergo neoadjuvant chemotherapy.

The rate of adequate sample is the most valuable outcome measure because it is independent of prevalence of malignancy in both groups. Multivariate regression analysis showed that team formation was significantly associated with an increased rate of adequate sample. The number of needle passes, needle type, needle diameter, use of suction, presence of on-site cytopathological evaluation, endosonographer experience and endosonographer training program were not significantly associated with the increased rate of adequate sample. It has to be noted, however, that limitations in sample size for each individual parameter prohibit a more detailed analysis.

This is the first study to explore the quality of and ways to improve quality of EUS-guided TA of pancreatic lesions in community hospitals. It is the first study to promote a regional multicenter team-based approach to improve outcome [21].

The retrospective nature of data collection in the BEFORE cohort is a potential limitation of the current study. Nevertheless, we selected consecutive cases in an attempt to limit selection bias. Another potential limitation is the variety of techniques and materials used. Choice of needles and other technical aspects of the procedure were at the discretion of the local clinicians. However, this was intentional as we were not testing the implementation or change of a single variable, for example, a specific needle type and size, but the behavior of the whole endosonography team within a hospital when regularly exposed to contact and interaction with colleagues from other hospitals jointly discussing potential ways to improve outcome.

A meta-analysis performed in 2012 showed higher sensitivity in prospective compared to retrospective studies, as well as in multicenter compared to monocenter studies [4]. We also observed this effect, which is most likely because of regular feedback and communication between centers. Moreover, the EUS team comprising endosonographers, nursing staff, cyto- technicians, and pathologists were aware that their performance was being monitored and compared to others. This effect on healthcare providers behavior is also known as the Hawthorne effect and is usually regarded as bias [22]. We argue that in the current study it is a desired effect, because of its positive effects on the quality of EUS-FNA while taking into consideration that it is not a one-time stimulus to behave differently, but a continuous incentive to do better as education and comparative performance measurements continue.

The results achieved after team formation are largely in line with performance targets regarding EUS-guided TA of solid pancreatic lesions proposed by the ASGE in 2015 [16]. Sensitivity after team formation is comparable to the pooled sensitivity of $85 \%$ reported by Hewitt et al. in their meta-analysis, and also in line with the ASGE performance target of $85 \%$. However, with a diagnostic yield of malignancy of $64 \%$, our results do not yet meet the proposed performance target of $70 \%$. Clearly this is an area for future improvement. The proposed ASGE performance targets are based on a multicenter retrospective study by Savides et al, with 1075 patients who underwent EUS-FNA of solid pancreatic lesions at 21 centers of which $81 \%$ were tertiary referral centers. In this publication it is stated that a diagnostic yield of less than $52 \%$ should prompt centers to evaluate reasons for their low yield [17].

Inclusion in the current study of solely community hospitals, all of which can be considered low-volume centers, shows that significant progress can be made regarding quality and yield of EUS-guided TA of solid pancreatic lesions by means of the formation of regional EUS interest group. We intend to continue and expand our collaborative activities, including prospective registration of data on EUS procedures, aiming for continuous improvement of outcome and care. We hope that expanding our prospective registry will allow us to clarify questions regarding the value of specific materials and techniques, such as presence of on-site cytopathological evaluation in EUS-guided TA of solid pancreatic lesions in community hospital practice in the future.

We would recommend that all centers performing EUS-guided TA continuously monitor their yield as a quality indicator. The most simple and straightforward way is to monitor the rate of adequate sample. If more than one of seven procedures yields an inadequate sample, additional measures should be undertaken including scrutinizing each aspect of the local protocol, initiating detailed communications with the local cytopathologist, and consulting local and/or regional colleagues.

\section{Conclusion}

In summary, formation of a regional EUS interest group with regular team meetings that include feedback on performance per center significantly improved the outcome of EUS-guided TA in patients with solid lesions of the pancreas in community hospitals and provides a framework for continuous improvement of care for these patients. 
Competing interests

None

\section{References}

[1] Eltoum IA, Alston EA, Roberson J. Trends in pancreatic pathology practice before and after implementation of endoscopic ultrasoundguided fine-needle aspiration: an example of disruptive innovation effect? Arch Pathol Lab Med 2012; 136: 447-453

[2] Dumonceau JM, Deprez PH, Jenssen C et al. Indications, results, and clinical impact of endoscopic ultrasound (EUS)-guided sampling in gastroenterology: European Society of Gastrointestinal Endoscopy (ESGE) Clinical Guideline - Updated January 2017. Endoscopy 2017; 49: $695-714$

[3] Hartwig W, Schneider L, Diener MK et al. Preoperative tissue diagnosis for tumours of the pancreas. B J Surgery 2009; 96: 5-20

[4] Hewitt M], McPhail M], Possamai L et al. EUS-guided FNA for diagnosis of solid pancreatic neoplasms: a meta-analysis. Gastrointest Endosc 2012; 75: 319-331

[5] Wani S, Wallace MB, Cohen J et al. Quality indicators for EUS. Gastrointest Endosc 2015; 81: $67-80$

[6] Alatawi A, Beuvon F, Grabar S et al. Comparison of 22G reverse-beveled versus standard needle for endoscopic ultrasound-guided sampling of solid pancreatic lesions. United European Gastroenterol ] 2015; 3: $343-352$

[7] Bang JY, Hebert-Magee S, Trevino J et al. Randomized trial comparing the 22-gauge aspiration and 22-gauge biopsy needles for EUS-guided sampling of solid pancreatic mass lesions. Gastrointest Endosc 2012; 76: $321-327$

[8] Fabbri C, Polifemo AM, Luigiano C et al. Endoscopic ultrasound-guided fine needle aspiration with 22- and 25-gauge needles in solid pancreatic masses: a prospective comparative study with randomisation of needle sequence. Dig Liver Dis 2011; 43: 647-652

[9] Iglesias-Garcia J, Dominguez-Munoz JE, Abdulkader I et al. Influence of on-site cytopathology evaluation on the diagnostic accuracy of endoscopic ultrasound-guided fine needle aspiration (EUS-FNA) of solid pancreatic masses. Am J Gastroenterol 2011; 106: 1705 - 1710

[10] Kamata K, Kitano M, Yasukawa S et al. Histologic diagnosis of pancreatic masses using 25 -gauge endoscopic ultrasound needles with and without a core trap: a multicenter randomized trial. Endoscopy 2016; 48: $632-638$

[11] Lee JK, Choi JH, Lee KH et al. A prospective, comparative trial to optimize sampling techniques in EUS-guided FNA of solid pancreatic masses. Gastrointest Endosc 2013; 77: 745 - 751

[12] Mohamadnejad M, Mullady D, Early DS et al. Increasing number of passes beyond 4 does not increase sensitivity of detection of pancreatic malignancy by endoscopic ultrasound-guided fine-needle aspiration. Clin Gastroenterol Hepatol 2017; 15: 1071 - 1078 e1072

[13] Park SW, Chung M], Lee SH et al. Prospective study for comparison of endoscopic ultrasound-guided tissue acquisition using 25- and 22 gauge core biopsy needles in solid pancreatic masses. PLoS One 2016; 11: e0154401

[14] Tarantino I, Fabbri C, Di Mitri R et al. Complications of endoscopic ultrasound fine needle aspiration on pancreatic cystic lesions: final results from a large prospective multicenter study. Dig Liver Dis 2014; 46: $41-44$

[15] Wani S, Cote GA, Keswani R et al. Learning curves for EUS by using cumulative sum analysis: implications for American Society for Gastrointestinal Endoscopy recommendations for training. Gastrointest Endosc 2013; 77: 558 - 565

[16] Wani S, Wallace MB, Cohen J et al. Quality indicators for EUS. Am J Gastroenterol 2015; 110: 102-113

[17] Savides T], Donohue M, Hunt G et al. EUS-guided FNA diagnostic yield of malignancy in solid pancreatic masses: a benchmark for quality performance measurement. Gastrointest Endosc 2007; 66: 277 - 282

[18] James PD, Hegagi M, Antonova L et al. Regional differences in use of endoscopic ultrasonography in Ontario: a population-based retrospective cohort study. CMAJ Open 2017; 5: E437-E443

[19] Campbell I. Chi-squared and Fisher-Irwin tests of two-by-two tables with small sample recommendations. Stat Med 2007; 26: 3661 - 3675

[20] Polkowski M, Jenssen C, Kaye P et al. Technical aspects of endoscopic ultrasound (EUS)-guided sampling in gastroenterology: European Society of Gastrointestinal Endoscopy (ESGE) Technical Guideline March 2017. Endoscopy 2017; 49: 989-1006

[21] Lee LS, Andersen DK, Ashida R et al. EUS and related technologies for the diagnosis and treatment of pancreatic disease: research gaps and opportunities-Summary of a National Institute of Diabetes and Digestive and Kidney Diseases workshop. Gastrointest Endosc 2017; 86: $768-778$

[22] Sedgwick P, Greenwood N. Understanding the Hawthorne effect. BM 2015; 351: h4672 